\title{
Westward moving dynamic substorm features observed with the IMAGE magnetometer network and other ground-based instruments
}

\author{
H. Lühr ${ }^{1, *}$, A. Aylward ${ }^{2}$, S. C. Bucher ${ }^{1 * *}$, A. Pajunpää ${ }^{3}$, K. Pajunpää ${ }^{4}$, T. Holmboe ${ }^{5}$, S. M. Zalewski ${ }^{6}$ \\ ${ }^{1}$ Institut für Geophysik und Meteorologie, Technische Universität Braunschweig, Mendelssohnstraße 3, D-38106 Braunschweig, Germany \\ ${ }^{2}$ Atmospheric Physics Laboratory, University College London, 67 Riding House St., London, W1P 7PP, United Kingdom \\ ${ }^{3}$ Finnish Meteorological Institute, Geophysical Research Division, P O Box 503, FIN-00101 Helsinki, Finland \\ ${ }^{4}$ Finnish Meteorological Institute, Nurmijärvi Geophysical Observatory, FIN-05100 Röykkä, Finland \\ ${ }^{5}$ University of Tromsø, Auroral Observatory, N-9037 Tromsø, Norway \\ ${ }^{6}$ Polish Academy of Sciences, Institute of Geophysics, Ks. Janusza 64, PL-01-452 Warsaw, Poland
}

Received: 30 April 1997 / Revised: 20 October 1997 / Accepted: 22 October 1997.

\begin{abstract}
We present the ground signatures of dynamic substorm features with particular emphasis on the event interpretation capabilities provided by the IMAGE magnetometer network. This array covers the high latitudes from the sub-auroral to the cusp/cleft region. An isolated substorm on 11 Oct. 1993 during the late evening hours exhibited many of well-known features such as the Harang discontinuity, westward travelling surge and poleward leap, but also discrete auroral forms, known as auroral streamers, appeared propagating westward along the centre of the electrojet. Besides the magnetic field measurements, there were auroral observations and plasma flow and conductivity measurements obtained by EISCAT. The data of all three sets of instruments are consistent with the notion of upward field-aligned currents associated with the moving auroral patches. A detailed analysis of the electrodynamic parameters in the ionosphere, however, reveals that they do not agree with the expectations resulting from commonly used simplifying approximations. For example, the westward moving auroral streamers which are associated with field-aligned current filaments, are not collocated with the centres of equivalent current vortices. Furthermore, there is a clear discrepancy between the measured plasma flow direction and the obtained equivalent current direction. All this suggests that steep conductivity gradients are associated with the transient auroral forms. Also self-induction effects in the ionosphere may play a role for the orientation of the plasma flows. This study stresses the importance of multi-instrument observation for a reliable interpretation of dynamic auroral processes.
\end{abstract}

\footnotetext{
*Present address: GeoForschungsZentrum Potsdam, Telegrafenberg, D-14473 Potsdam, Germany

Present address: Solar Terrestrial Environment Laboratory,

Nagoya University, Honohara 3-13, Toyokawa, 442 Japan
}

Keywords. Ionosphere (Auroral ionosphere; Electric fields and currents; Ionosphere-magnetosphere interactions).

\section{Introduction}

Ground-based magnetic field measurements have been used for more than a century to investigate the electrodynamics of ionospheric current systems (e.g. Birkeland, 1908; Chapman, 1935). Now new groundbased measurement techniques such as coherent and incoherent radars or imaging riometers that observe the ionosphere remotely, have become available. These new facilities together with space-born instrumentation have made it possible to draw a unique picture of the three dimensional current systems connecting the magnetosphere and ionosphere, thus resolving the ambiguity arising when current systems are derived solely from ground-based magnetic field observations (Fukushima, 1976). In spite of that limitation magnetometer arrays have proved to be a very powerful tool for characterising the types of auroral phenomena and for determining their temporal and spatial developments. A great number of useful techniques for utilising magnetic field data when interpreting auroral phenomena have been developed in association with the International Magnetospheric Studies (IMS) (see Untiedt and Baumjohann, 1993 for a review). One of the most recent famous discoveries made with magnetometer arrays is the identification of travelling convection vortices (TCV) (Friis-Christensen et al., 1988; Glaßmeier et al., 1989).

In this study we investigate a substorm period in the pre-midnight sector showing many of the classical features. Well-known in this respect are the westward travelling surges (WTS) (Akasofu et al. 1965). The WTS is a spectacular and highly dynamic phenomenon. At a pre-existing stable arc the intensity suddenly increases and it expends poleward and westward. The shape of 
westward propagating auroral band resembles that of a surge on the ocean running onto the beach. Observed velocities of WTS range from several to ten kilometers per second (e.g. Opgenoorth et al., 1983). In the magnetogrammes their appearance mark the onset of a substorm. In the surge head, a strong upward fieldaligned current flows, which is believed to divert the westward electrojet at its western end into the magnetosphere. A comprehensive description of the electrodynamics in the ionospher associated with a WTS has been given by Opgenoorth et al. (1983). Subsequent to a WTS sometimes less spectacular auroral bright spots show up which also propagate westward but at a speed of the order of $1 \mathrm{~km} / \mathrm{s}$ (see Nakamura et al., 1993 or Elphinstone et al., 1996 for a review). These features, named auroral streamers, have received only a little attention in the literature up to the present.

In the magnetogrammes the auroral streamers generate a variation predominantly in the eastward component when passing by. Because of the fast motion of the features, information obtained by a single magnetometer is of limited value. More suitable are arrays of stations, since the drift velocity of the structure can be inferred from the date of two or more sufficiently widely separated magnetometers. Furthermore, magnetometer data can be used to construct maps of equivalent ionospheric currents. These equivalent current patterns are not easy to interpret, if the conductivity exhibits spatial gradients, as expected in the presence of discrete auroral forms. Here incoherent scatter radar data can complement the picture. With tristatic systems like EISCAT, the electric field vector and the conductivity distribution at a single point can be determined simultaneously, thus allowing us to separate the observed ionospheric currents into their Hall and Pedersen components. Data from magnetometer arrays, on the other hand, are vital for radar observers in order to distinguish between temporal variations in the radarderived quantities and those caused by auroral structures moving through the radar beam.

In a study of $\Omega$-bands Lühr and Schlegel (1994) have demonstrated the value of combined magnetic field and radar data sets. Special attention was paid in that study to the precise phasing of the measurements at the different sites with respect to the moving current structures. We make use of the same technique in order to find out for the westward drifting auroral structures the spatial relationships between peaks in ionospheric currents, electric fields, conductivities and auroral luminosity.

In the following we will first present a short introduction of the IMAGE magnetometer network and then describe the All-Sky-Camera (ASC) and EISCAT data used in this study. In Sect. 3 the observations obtained by all three sets of instruments during our event on 11 October 1993 are presented. Subsequently we combine the measurements of the various facilities trying to achieve a picture of the phenomenon that is as comprehensive as possible. Finally we make an attempt to fit our observations in the global picture of a substorm.

\section{Instrumentation and data sets}

The magnetic field observations used in this study have been obtained by the International Monitor for Auroral Geomagnetic Effects (IMAGE) magnetometer network. Within this project there are 15 ground-based magnetometers covering the range from sub-auroral through auroral latitude, up to cusp/cleft regions in the European sector. Figure 1 shows the location of the stations and their names, co-ordinates of the sites are listed in Table 1. Key features of the IMAGE magnetometer network have earlier been published in STEP International (Lühr, 1994).

The IMAGE project is a joint venture of six European institutions. The tasks to be covered by the groups include: supplying the instruments and ensuring their maintenance; retrieving, pre-processing and correcting the data; distributing plots and data tapes among the members. The final data are stored in a common ASCII format which has been described earlier (IAGA News, 20, 112, 1981).

The magnetometers deployed in this project are not all of the same type. The groups providing hardware have installed those kinds of instruments they are most

IMAGE Magnetometer Network

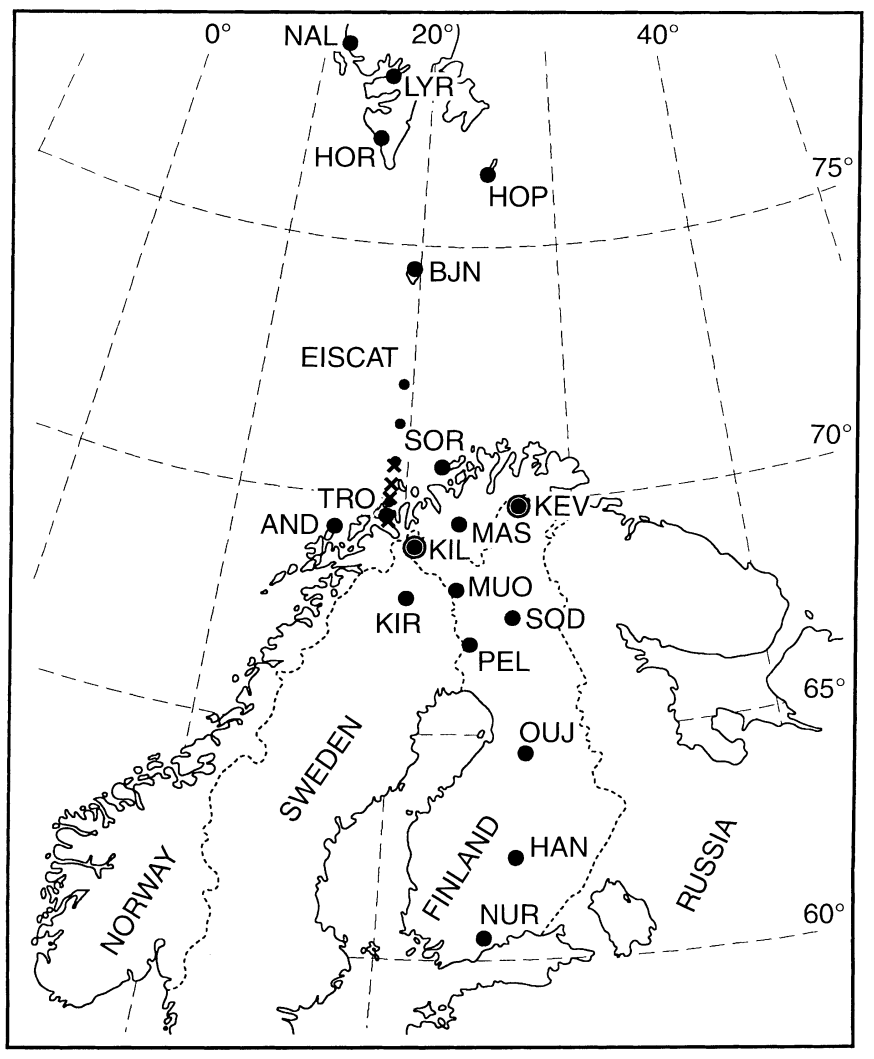

Fig. 1. Map of northern Europe showing the instrument sites. Solid dots mark the locations of the magnetometer stations. The two encircled dots identify the sites of the all-sky cameras. The ionospheric footprints of the four EISCAT common volumes for determining the flow velocities are marked by small dots. Crosses indicate the positions of conductivity measurements 
Table 1. Locations of the magnetometer stations IMAGE (International Monitor for Auroral Geomagnetic Effects)

\begin{tabular}{|c|c|c|c|c|c|c|}
\hline \multirow[t]{2}{*}{ Station name } & \multirow[t]{2}{*}{ Code } & \multicolumn{2}{|c|}{ Geographic } & \multicolumn{2}{|c|}{ AACGM magnetic ${ }^{\mathrm{a}}$} & \multirow{2}{*}{$\begin{array}{l}\text { Approximate } \\
L \text {-value }\end{array}$} \\
\hline & & Latitude & Longitude & Latitude & Longitude & \\
\hline Ny Ålesund & NAL & 78.92 & 11.95 & 75.9 & 112.7 & - \\
\hline Longyearbyen & LYR & 78.20 & 15.82 & 75.0 & 113.4 & - \\
\hline Hornsund & HOR & 77.00 & 15.60 & 73.9 & 110.8 & 15.8 \\
\hline Hopen Island & HOP & 76.51 & 25.01 & 72.7 & 116.2 & 11.5 \\
\hline Bear Island & BJN & 74.50 & 19.20 & 71.2 & 109.2 & 10.3 \\
\hline Sørøya & SOR & 70.54 & 22.22 & 67.0 & 106.9 & 7.1 \\
\hline Tromsø & TRO & 69.66 & 18.94 & 66.3 & 103.6 & 6.7 \\
\hline Andenes ${ }^{\mathrm{b}}$ & AND & 69.30 & 16.03 & 66.1 & 101.1 & 6.5 \\
\hline Kevo & KEV & 69.76 & 27.01 & 65.9 & 109.8 & 6.4 \\
\hline Masi & MAS & 69.46 & 23.70 & 65.8 & 107.1 & 6.4 \\
\hline Kilpisjärvi & KIL & 69.02 & 20.79 & 65.5 & 104.5 & 6.3 \\
\hline Muonio & MUO & 68.02 & 23.53 & 64.3 & 105.8 & 5.7 \\
\hline Kiruna $^{\mathrm{b}}$ & KIR & 67.83 & 20.42 & 64.3 & 103.2 & 5.7 \\
\hline Sodankyläb & SOD & 67.37 & 26.63 & 63.5 & 107.8 & 5.4 \\
\hline Pello & PEL & 66.90 & 24.08 & 63.1 & 105.4 & 5.2 \\
\hline Oulujärvi & OUJ & 64.52 & 27.23 & 60.5 & 106.5 & 4.3 \\
\hline Hankasalmi & HAN & 62.30 & 26.65 & 58.2 & 104.9 & 3.7 \\
\hline Nurmijärvi & NUR & 60.50 & 24.65 & 56.4 & 102.5 & 3.4 \\
\hline
\end{tabular}

${ }^{\text {a }}$ Altitude Adjusted Corrected Geomagnetic coordinates (Baker and Wing, 1989)

b Added to the IMAGE data set from mid 1996

familiar with. All magnetometers meet, however, certain standards in calibration, stability and frequency response ensuring that a homogeneous set of data emerges from the measurements. Samples are taken at $10 \mathrm{~s}$ intervals and the resolution of the instruments is $1 \mathrm{nT}$ or better. Special attention is paid to a precise timing of the readings. This is particularly important when velocities of current structures are deduced from propagation delays between stations.

The instruments in the northern part of the Scandinavian mainland [Sørrøya (SOR), Masi (MAS), Kevo (KEV), Kilpisjärvi (KIL), Muonio (MUO) and Pello (PEL)] were supplied by the Technical University of Braunschweig. They formerly constituted the "EISCAT Magnetometer Cross" which was in continuous operation from October 1982. The devices that sense the magnetic fields are three orthogonal fluxgate sensors of the double rod type. Output voltages are digitised to 12 bit words providing a dynamic range of $\pm 2000 \mathrm{nT}$ at a resolution of $1 \mathrm{nT}$. The internal sampling rate is $3.2 \mathrm{~Hz}$, but readings are averaged over $10 \mathrm{~s}$ before recording. Once per day an automatic self-check is initiated which allows us to assess the performance of critical components and which also includes a calibration of the sensitivity. The results of the test are recorded and analysed during the data processing. Highly stable quartz crystal oscillators guarantee a time accuracy to a few seconds throughout the year. Stations are powered generally by line power, but back-up batteries are installed which can bridge power breaks up to 24 hours. A detailed description of these stations base been given by Lühr et al. (1984).

The three southernmost stations Nurmijärvi (NUR), Hankasalmi (HAN) and Oulujärvi (OUJ) joined the IMAGE network in Autumn 1992. NUR is identical with the Nurmijärvi Geophysical Observatory of the
Finnish Meteorological Institute and HAN is its field station. OUJ is run by the Geophysical Observatory of Oulu University. They all are equipped with fluxgate magnetometers (FGM) made by the Danish Meteorological Institute. For redundancy purposes NUR is also running a Polish torsion photo-electric magnetometer (TPM), as at Hornsund. The magnetometers have dynamic ranges $\pm 3000 \mathrm{nT}$ and the resolution is $0.1 \mathrm{nT}$. The sensors are in temperature stabilised rooms and the baseline stability of the magnetometers is better than $\pm 5 \mathrm{nT}$ per year. Accurate timing is provided by GPS or Omega receivers. Data are collected on computer hard discs and transferred via telephone lines from HAN and OUJ to the Nurmijärvi observatory for processing.

At the Polish Polar Station Hornsund on Spitsbergen, continuous recordings of the Earth's magnetic field have been carried out by means of a portable magnetometer station since 1978. The sensing elements are three quartz torsion variometers of Bobrov type, utilising photo-electric converters which transform the variations of three geomagnetic elements into voltage changes. Starting from July 1985 data have been stored digitally on magnetic tapes. In August 1993 a redundant set of new data recorders were installed, which provide a four times better resolution $(\sim 0.1 \mathrm{nT})$. The data are read out from the internal memory with a PC. Floppy disks are the medium on which the data are transported back to base. On joining the IMAGE project in October 1993, the sampling was changed from $30 \mathrm{~s}$ to $10 \mathrm{~s}$ and furthermore the orientation of the sensor elements were aligned to geographic directions $(\mathrm{X}, \mathrm{Y}, \mathrm{Z})$. The timing of the recordings is controlled by the precise station clock. Absolute measurements of the magnetic elements D, I, F are performed frequently to check and improve the stability of the base lines. 
In addition, since October 1993 the four stations on the Svalbard archipelago Bear Island (BJN), Hopen Island (HOP), Longyearbyen (LYR), Ny Ålesund (NAL) and the station Tromsø (TRO) have been part of the IMAGE magnetometer network. All of them are operated by the University of Tromsø. The instruments are fluxgate magnetometers fabricated by the University of Tromsø. The sensors are of the double rod/Vacquier type. An electronics unit with internal A/D-converter and a standard PC for data recording are used. The signals are digitised to a resolution of $1 \mathrm{nT}$ and the dynamic range is $\pm 8000 \mathrm{nT}$. The internal sampling rate is $2.5 \mathrm{~Hz}$, but only averages over $10 \mathrm{~s}$ are recorded. The timing accuracy of the recordings is continuously improved. By September 1995 the stations NAL, LYR, BJN and TOR were equipped with a GPS clock receiver assuring an accuracy better than a second. HOP was upgraded in summer 1996. Absolute measurements are performed once or twice a year. The stability of the base lines is $1-2 \mathrm{nT} / \mathrm{y}$, except for HOP, due to problems with permafrost there.

By the time of publication, data from three more observatories (Andenes, Kiruna and Sodankylä) are being routinely added to the IMAGE network. Coordinates of these sites are included in Table 1. For checking the actual status of the network we recommended readers to visit the WWW-site (http:// www.geo.fmi.fi./image/).

The Finnish Meteorological Institute is operating four All-Sky-Cameras (ASCs) in the Scandinavian sector (KEVo, KILpisjärvi, MUOnio, SODankylä) and one on Spitsbergen (HORnsund). Pictures are taken by a $16 \mathrm{~mm}$ Paillard Bolex camera looking into a spherical mirror from above. The mirror reflects the whole sky into the camera. In this way auroras appear as seen from above. In addition each picture contains a digital time display on the east-side and radioactive lights as standards for the colours. A crystal clock controls the time of exposure to within a second. The interval between the pictures can be selected from $20 \mathrm{~s}$ to $1 \mathrm{~h}$ ( $1 \mathrm{~min}$ in this case) and the exposure time can be set from 2 to $16 \mathrm{~s}$ ( $2 \mathrm{~s}$ in this case). The camera is installed in the centre of the image blacking out a cone of $30^{\circ}$. This black spot can be used to estimate spatial scales of auroras.

On 11 October 1993, from 1200 UT until 1900 UT, the EISCAT radars were running the UK Special Programme MTVU. This was intended primarily for topside studies. Both UHF and VHF systems were in operation. The VHF was running a variant of Common Programme 7 , measuring vertically above Tromsø. This data is not used in the current study, and so will not be described further. Intended as a means of mapping the magnetic field lines intersecting the VHF beam at various heights, the UHF ran a 4-point elevation scan in a vertical plane offset $2.5^{\circ}$ east of north. It measured for approximately 1 minute each at $43.6^{\circ}, 55^{\circ}, 70^{\circ}$ and $90^{\circ}$ elevation, taking 5 -min for the cycle allowing for movement time. The Tromsø UHF made full spectral measurements from $200 \mathrm{~km}$ range to $956 \mathrm{~km}$ range in increments of $31.5 \mathrm{~km}$ (though the gates overlap to some extent). It also measured a power profile from $75 \mathrm{~km}$ to $447 \mathrm{~km}$ range in $2.1 \mathrm{~km}$ increments. The difference between "spectral measurements" and "power profile" measurements is that a fit for the full set of plasma parameters can only be made on the former, the power profile gives only a profile of returned power with range. The power profile is, however, primarily a measure of electron density, and so can be used, with some assumptions, to give a range profile of electron density, to within about $20-30 \%$ accuracy.

The flow velocity vectors have been derived from the simultaneous measurements at the three sides Tromsø, Kiruna and Sodankylä from a common volume at $280 \mathrm{~km}$ altitude. Vector velocities derived from the position furthest north are more noisy than desirable. Because of the close alignment of the Tromsø and Kiruna beam, the uncertainty is mainly confined to the east-west component.

\section{Observations}

The event we are going to study occurred on 11 October 1993. This day was moderately active with $K p$ ranging between 3.0 and 5.3. There are unfortunately no interplanetary magnetic field (IMF) data available for that day. We therefore do not have direct information on the energy input into the magnetosphere. Some indirect information may be obtained from the readings of globally distributed magnetometers, as published in "Provisional Geomagnetic Data Plots" by Kyoto University. At 1415 UT we find, globally, a sudden enhancement in the ionospheric plasma convection which is probably caused by an elevated solar wind input to the magnetosphere. Also in the Scandinavian sector 1415 UT marks the onset of enhanced activity, especially at Svalbard stations (see Fig. 2).

The event studied in some detail is the substorm commencing at 1710 UT (Fig. 2). Scandinavia was located at the westward end of the electrojet during this event. There was no indicating of a negative bay at Iceland stations. Worth mentioning are the peculiar variations in the $\mathrm{Y}$ (eastward) component between 1700 and 1800 UT right in the middle of the substorm (Fig. 2). These wave-like structures are at the focus of this study.

\subsection{Magnetic field observations}

In this section we present the features of the event which emerge from the magnetic observations. Figure 3 shows the magnetic field variations at the IMAGE network during 17 to $18 \mathrm{UT}$, the time of interest. As mentioned before we observe a well-isolated substorm during this hour. The onset of the substorm is heralded at stations south of SOR by short-lived positive excursions in the $\mathrm{X}$ and Y components at 1711 UT. Such a feature at the beginning of a substorm is indicative of the passage of a westward travelling surge (WTS) over the chain of stations. Subsequent to the WTS the X component 

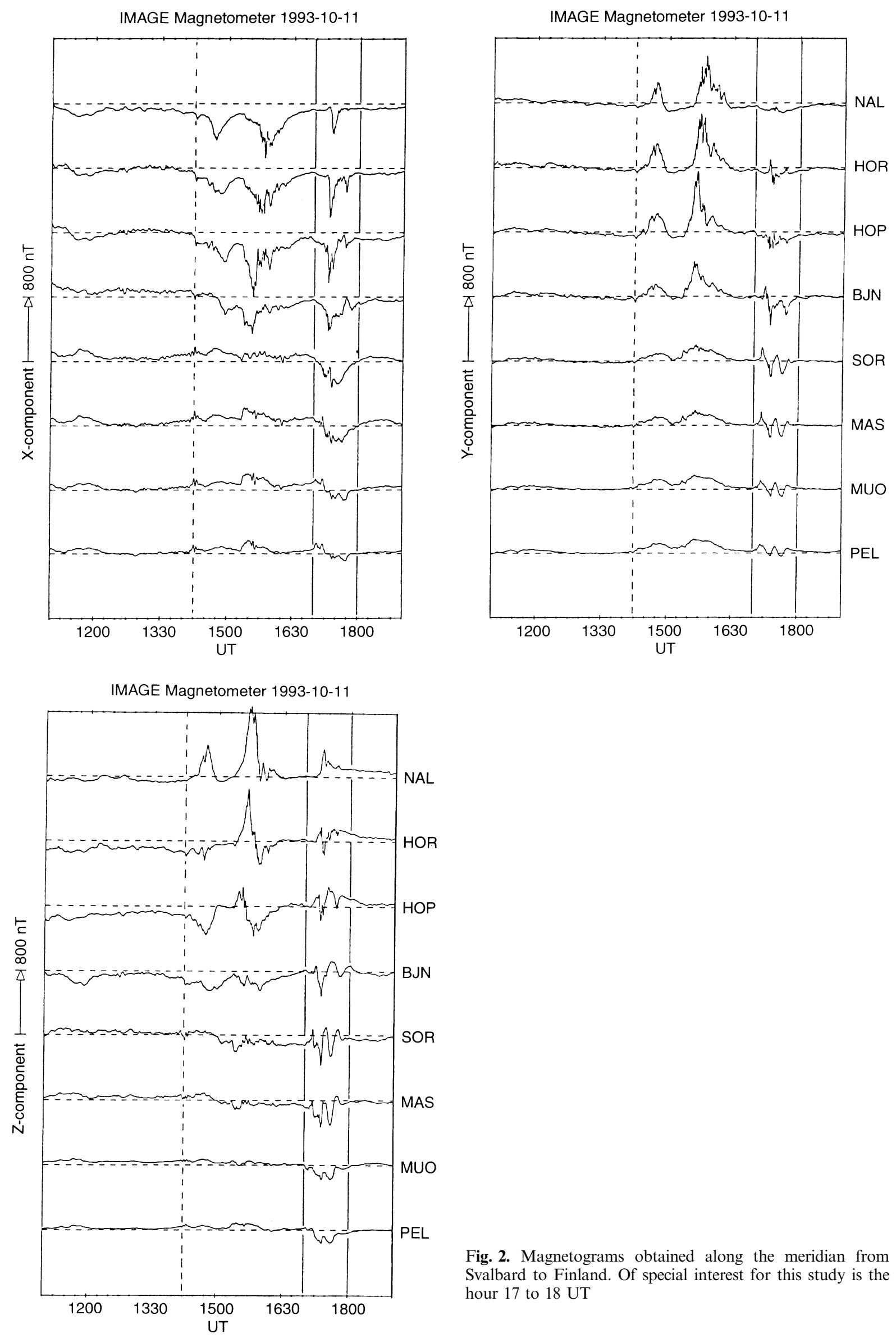

Fig. 2. Magnetograms obtained along the meridian from Svalbard to Finland. Of special interest for this study is the hour 17 to $18 \mathrm{UT}$ 
IMAGE Magnetometer 1993-10-11

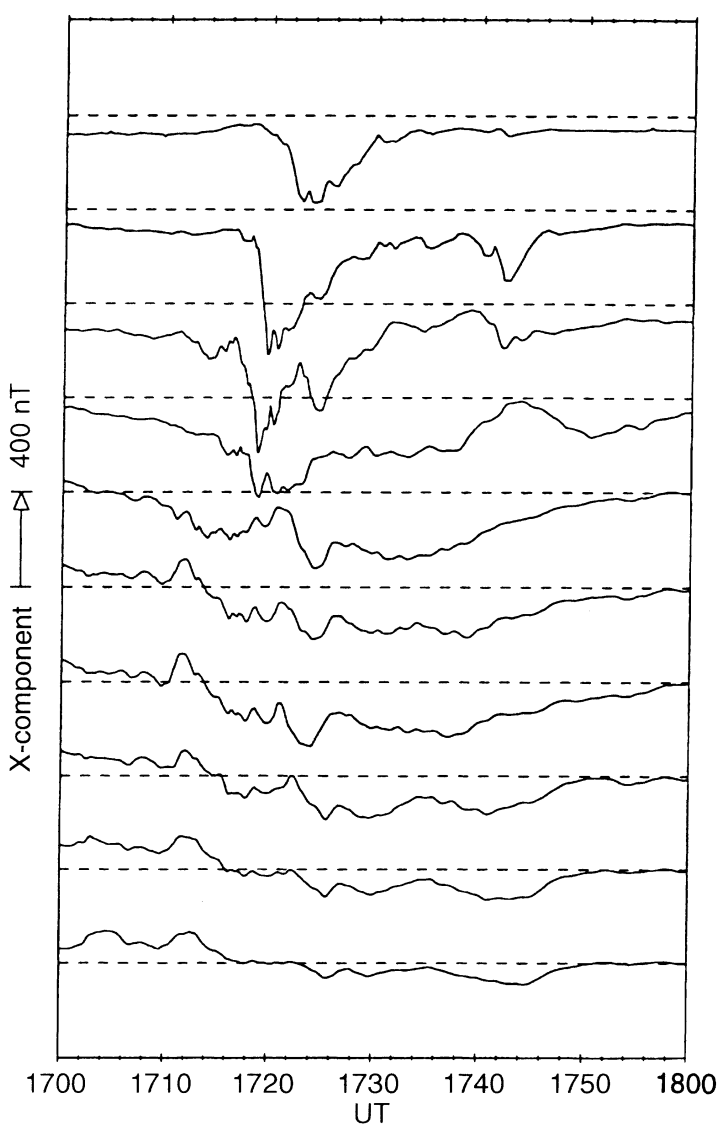

IMAGE Magnetometer 1993-10-11

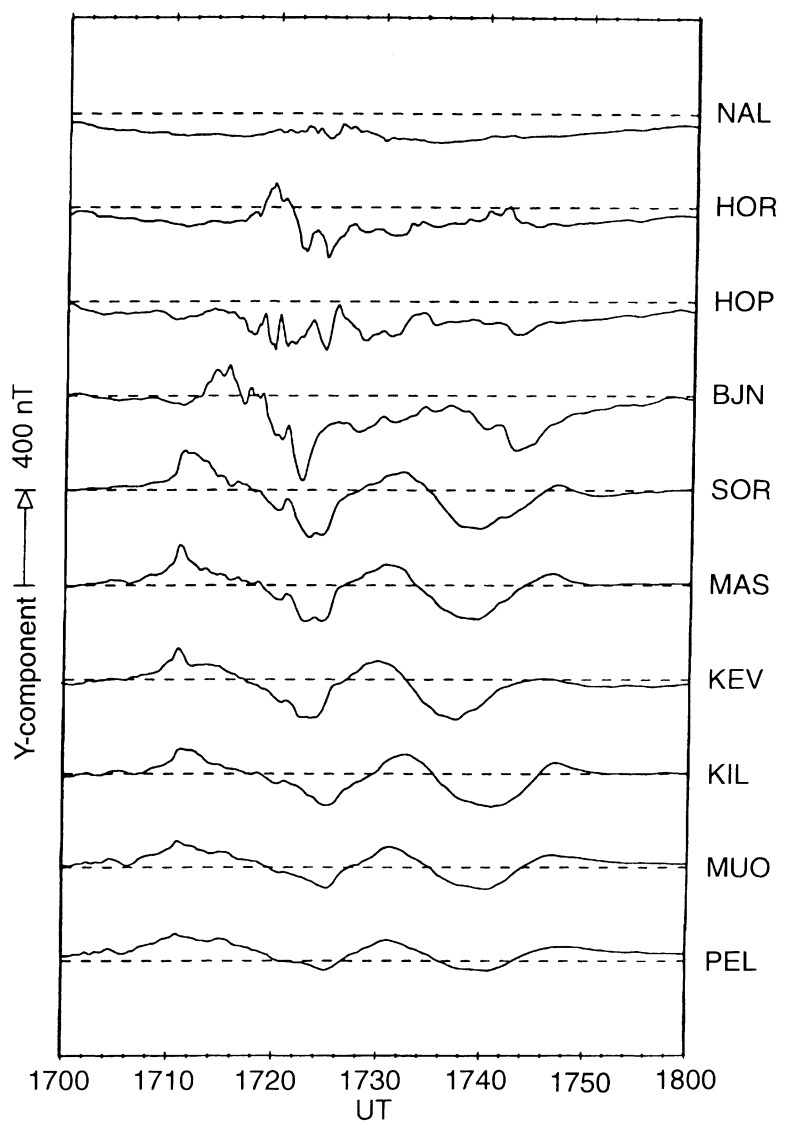

Fig. 3. Magnetograms of the substorm under study. The sinusoidal variation of the Y component will be investigated in some depth

becomes negative, first at SOR then at BJN and it continues to be progressively delayed at stations further north. The lifetime of the negative bay is, in the north, relatively short (10 $\mathrm{min}$ at NAL) compared to that at southern stations. By about 1750 UT the field components at all stations are back to undisturbed levels.

A remarkable feature in the $\mathrm{Y}$ (eastward) components at all stations south of $\mathrm{BJN}$ is a sinusoidal variation comprising two full cycles. The period of these waves starting at $1720 \mathrm{UT}$ is about $17 \mathrm{~min}$. A comparison of the stations on the flanks reveals that the signature appears delayed by about $3 \mathrm{~min}$ at KIL, located to the west of the chain, with respect to KEV which is some $250 \mathrm{~km}$ further east. Such a propagation delay implies a moving current system as the cause for these variations in $\mathrm{Y}$.

The $\mathrm{Z}$ (vertical) component (not shown here) is influenced both by the westward electrojet evident in the $\mathrm{X}$ component and by the moving current structures revealed from the variations in $Y$. On average we find a positive deflection of the $\mathrm{Z}$ component at stations north of BJN and a negative excursion south of it. This implies an average location of the electrojet close to BJN. At the time of the sinusoidal waves in $\mathrm{Y}$ we see similar variations in $\mathrm{Z}$ but the latter lead the former by about $60^{\circ}$ in phase. This relation favours also the idea of a westward propagation of some current features.
We stated already that the westward electrojet first appeared at station SOR and subsequently propagated poleward. The dynamics of the electrojet can best be assessed when looking at latitude profiles, which give a synoptic view of the magnetic deflections along a magnetic meridian. Figure 4 shows magnetic profiles for four different times. The $\mathrm{X}$ (northward) component can be regarded as a first order measure for the electrojet intensity and its north/south extent, $\mathrm{Y}$ (eastward) should be zero everywhere for an electrojet flowing due east/west. $Z$ is expected to be negative in the south and positive in the north of a westward electrojet. The first three frames in Fig. 4 show the situation after the substorm onset. In all cases we have a negative deflection of $\mathrm{X}$, which is indicative of a westward electrojet. The peak amplitude propagated northward at a rate of about $2^{\circ}$ in latitude per $3 \mathrm{~min}$. At 1723 UT the jet had reached its northernmost position with the centre close to $78^{\circ}$ geographical latitude $\left(75^{\circ}\right.$ magnetic latitude). Just after the onset at 1712 UT the electrojet centre was near SOR $\left(70.5^{\circ}\right.$ geographic latitude). It hence propagated poleward about $800 \mathrm{~km}$ at an almost constant speed of $1.2 \mathrm{~km} / \mathrm{s}$. The intensity of the electrojet increased until it reached the peak amplitude just before 1720 UT (see Fig. 4, Frame 2) and decayed gradually until 1730 UT. 

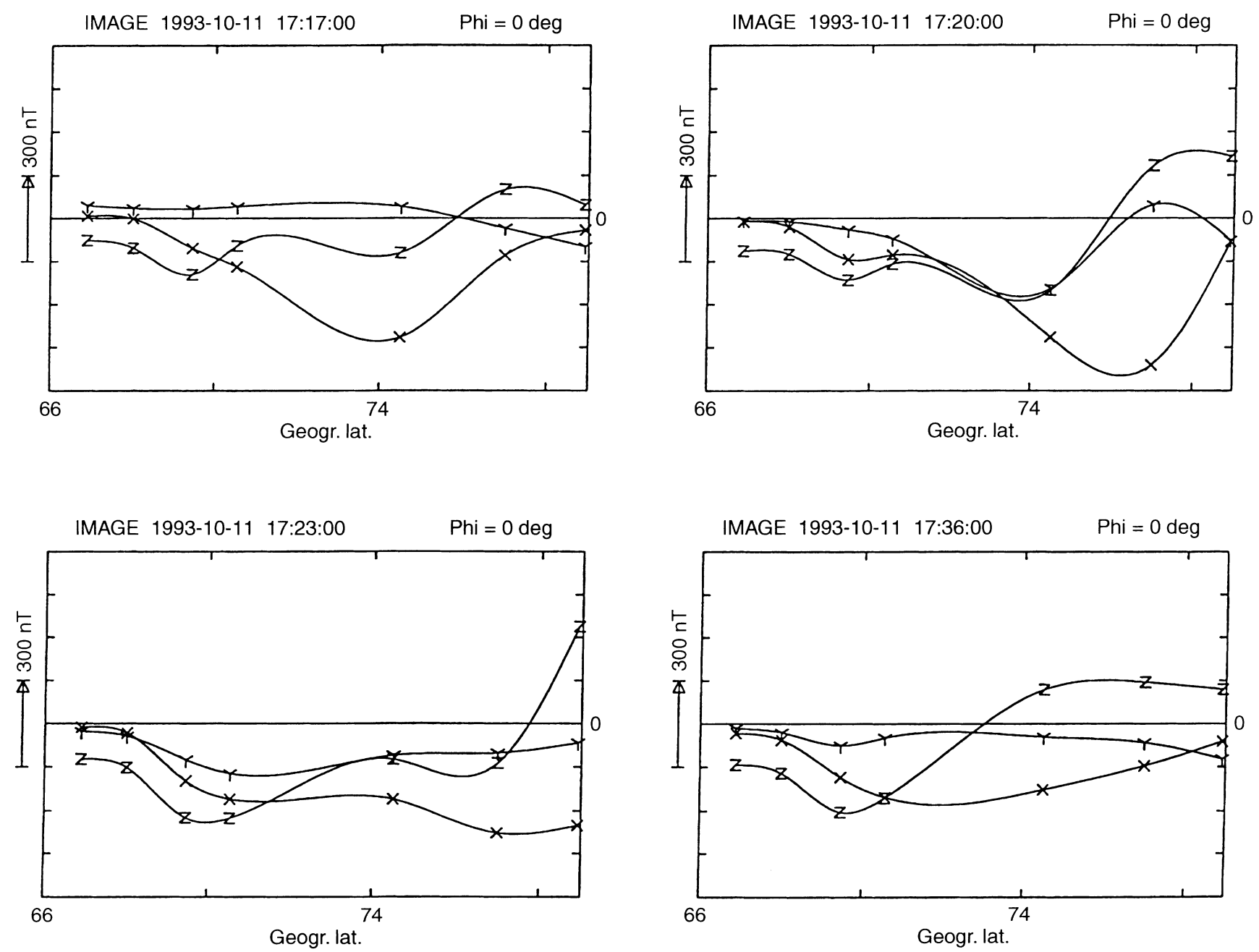

Fig. 4. Latitudinal profiles of the magnetic deflections. The westward electrojet, indicated by the minimum, in X propagates poleward in the first three frames. By the time of the third frame a new electrojet forms which is more or less stationary for the subsequent 30 min

At the time of Frame 3 (1723 UT) a new electrojet formed further south near SOR. This one persisted until 1745 UT and did not move much in latitude. The last frame in Fig. 4 shows that we had a clear single electrojet configuration around 1736 UT. The interpretation of the $\mathrm{Y}$ and $\mathrm{Z}$ components in these latitude profiles is not straight forward, since there were, in addition to the electrojet smaller-scale current structures moving overhead the stations.

A more appropriate way of visualising the moving current structures is to plot the distribution of equivalent currents. These are pseudo currents in the ionosphere which could be the cause for the observed magnetic field variations. Assuming that the scale size of the current structure is much larger than the ionospheric height, we may write for the equivalent currents.

$J_{X}=-2 / \mu_{0} B_{Y}, \quad J_{Y}=2 / \mu_{0} B_{X}$

where $\mu_{0}$ is the permeability of free space and $B_{X}$ and $B_{Y}$ are the magnetic field deflections on the ground.

The purpose of the equivalent current plot in Fig. 5 is to assess the features of the smaller-scale current structures. For that reason the data have been high- pass filtered by subtracting a running average over 20 min prior to plotting. In this way we get rid of the dominating contributions from the electrojet. Figure 5 shows the traces of equivalent currents plotted along the latitude of the various stations. Exceptions are KEV and KIL on the flanks which have been included for reference at the bottom.

The first prominent feature in Fig. 5 appeared at 1710 UT with strong southward currents. During the subsequent minutes these turned towards west at SOR and towards east at all stations south of SOR. A feature like this has previously been identified by Opgenoorth et al. (1983) as the ground signature of a westward travelling surge (WTS). The surge head is suggested from these signatures at a latitude close to SOR.

Prominent features at later times are a sequence of current vortices with alternating directions of rotation. The first, centred at 1726 UT, rotated clockwise, the next at 1735 UT anti-clockwise and the last, another 8 min later, clockwise again. These vortices were also observed at the stations on the flanks. There is a remarkable similarly between the signatures at the two sites, but variations show up 3 min earlier at $\mathrm{KEV}$, in 


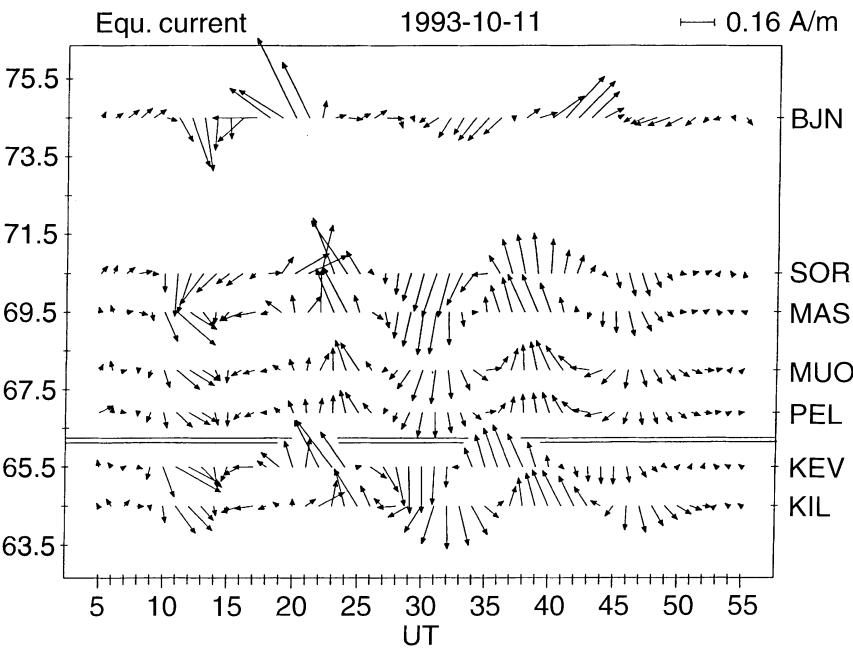

Fig. 5. Map of equivalent ionospheric currents (north to the top, east to the right). A running average over $20 \mathrm{~min}$ has been subtracted from the data before plotting

the east, than at KIL. These characteristics imply that the sinusoidal variations in the $\mathrm{Y}$ component were caused by current vortices, varying only little in time, but drifting westward overhead the stations.

The drift velocity can be estimated by determining the signal propagation delay between KEV and KIL. With the help of a cross-correlation analysis we obtained a time delay of $20 \mathrm{~s}$ for the WTS and $170 \mathrm{~s}$ for the drifting vortices. Considering the distance of $250 \mathrm{~km}$ between KEV and KIL these times convert to $12 \mathrm{~km} / \mathrm{s}$ and $1.5 \mathrm{~km} / \mathrm{s}$ for the WTS and vortices, respectively. Because of the 10-s-sampling the relative uncertainty in the velocity is considerably larger for the WTS. Furthermore, since we have only a two-point measurement, it is impossible to decide whether the surge really travelled at this high speed or whether the short delay is caused by a combined effect of expanding and travelling.

Knowing the velocity of the current vortices we can estimate their spatial scales. The centres are separated in the time series by 8 to $9 \mathrm{~min}$ which converts to a diameter of $750 \mathrm{~km}$ in east/west direction. For estimating the north/south extent it seems to be reasonable to take the latitude where the currents have reached half their amplitude which occurs at PEL. With this convention we again get a scale size of more than $700 \mathrm{~km}$ for the diameter in this direction. Thus, the equivalent currents seem to form a fairly circular pattern.

Vortices of equivalent currents tend to surround field-aligned current filaments reaching into the ionosphere. Due to the current continuity, the FACs have to be closed in the ionosphere

$j_{\prime \prime}=\operatorname{div} \mathbf{J}$

where $\mathbf{J}$ is the height integrated current density in the ionosphere. With a homogeneous conductivity distribution only Pedersen current contributes to the current closure. Under those conditions the electric fields, which are aligned with the Pedersen currents form, convergent patterns around upward-directed FACs and a divergent pattern around downward FACs.

The magnetic field deflections on the ground are caused in the first case by ionospheric Hall currents. For large-scale currents and homogeneous conductivities the simple relation holds

$\mathbf{b}=\mu_{0} /\left(2 B_{0}\right) \mathbf{J}_{H} \times \mathbf{B}_{0}=1 / 2 \mu_{0} \Sigma_{H} \mathbf{E}$

where $\mathbf{b}$ is the magnetic deflection on the ground, $\mathbf{J}_{H}$ the height integrated Hall current density, $B_{0}$ the ambient magnetic field, $\Sigma_{H}$ the height integrated Hall conductivity and $\mathbf{E}$ the ionospheric electric field. It is evident from Eq. (3) that under these simplifying conditions the magnetic field deflections on the ground are co-aligned with the ionospheric electric fields.

Figure 6 shows the horizontal component of the magnetic field deflection. Here again we have used the high-pass filtered data. Therefore the contribution of the prevailing electrojet is suppressed. As stated already these vectors can in the first instance be interpreted as the electric field distribution.

Quite prominent in this figure are two regions of diverging vectors around 1726 and 1743 UT. Clearly converging vectors appear at 1735 UT and are a little less clear at $1718 \mathrm{UT}$. The two traces at the bottom show again the time delay between the stations KEV and KIL. According to the electric field signature mentioned our measurements suggest a sequence of upward, downward, upward, and downward FAC filaments between 1718 and 1743 UT. The deflection vectors just after 1711 UT which are associated with the WTS, are hard to interpret in terms of electric fields, since steep conductivity gradients are known to exist in the vicinity of a WTS (Kirkwood et al., 1988).

From these presented observations we deduced the dynamics of the electrojet, determined the size and velocity of embedded smaller-scale current systems, and localised the centres of FAC filaments. For all these assessments assumptions had to be made. Observations from other facilities are required for validation.

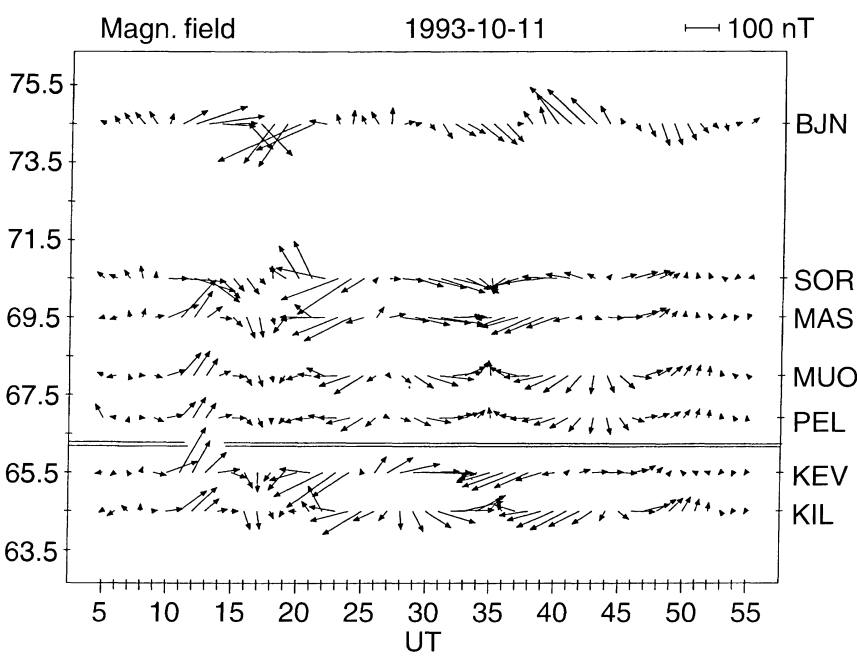

Fig. 6. Map of horizontal magnetic field disturbance vectors. Same format as Fig. 5 


\subsection{Auroral observations}

To back up the magnetic field observations presented in the previous section we present here the all-sky camera photos taken at the stations KIL and KEV. Since this substorm occurred quite early in the evening, light conditions were not too favourable at KIL until $1730 \mathrm{UT}$. At KEV, $5^{\circ}$ further east, good auroral images could be obtained from about 1700 UT onward.

Individual stages of the auroral development are shown in Fig. 7. In the beginning from 1700 to 1710 UT there is a relatively stable discrete arc running from east to west through the zenith of KEV. As an example three consecutive frames from 1703 to 1705 UT are shown. An auroral bulge formed at 1710 UT to the east of KEV and on the poleward boundary of the pre-existing discrete arc. One minute later it passed north of KEV (see Fig. 7) and at 1712 UT the bulge has reached already KIL (not shown here because of low contrast).

Another auroral feature showed up to the east of KEV at 1714 UT. This one also moved westward but at slower speed. Around 1715 UT it passed the zenith of KEV (Fig. 7). The daylight was still too bright at KIL to determine the arrival time of the auroral form there.

A last auroral patch formed again northeast of KEV at 1730 UT. One minute later it passed overhead KEV on its way to the west. At this time conditions were better at KIL and we can identify the arrival time at KIL (1734 UT) from the last three frames in Fig. 7. The rest of the hour until 1800 UT was completely void of auroral activity.

The auroral observations made during the hour of interest (1700-1800 UT) can be summarised as follows. Immediately after sunset there was a stable arc at the zenith of KEV running from east to west. At 1710 UT an auroral bulge formed poleward of the arc and travelled at high speed westward. This auroral feature is consistent with our interpretation of the magnetic signatures at that time being caused by a WTS. At 1715 and again at 1731 UT north-south elongated auroral features passed overhead KEV on their way to the west. The last one at least was observed 3 min later over KIL. Here again we find a convincing match between the appearance of the auroral forms and the formation of upward FACs, as deduced from magnetic field observations. Also the westward propagation speed found with both systems is identical. A direct comparison of the times when the auroras passed overhead with the prediction of the FAC centres from Fig. 6 reveals, however, a systematic difference. The auroral features were in the zenith of KEV at 1715 and 1731 UT while the estimates from the magnetic measurements give 1717 and 1733 UT. At KIL we reveal 1734 and 1736 UT from the optical and magnetic measurements, respectively. The aurora appeared systematically 2 min earlier than expected from magnetic variations. A discussion of this apparent discrepancy will be presented in a later section.

\subsection{EISCAT measurements}

A clue towards understanding of the slight but systematic discrepancy between optical and magnetic observations regarding the position of upward directed FACs might be offered by the EISCAT measurements. Before going into these details we present the two parameters, plasma velocity and ionospheric conductances which were obtained by EISCAT.

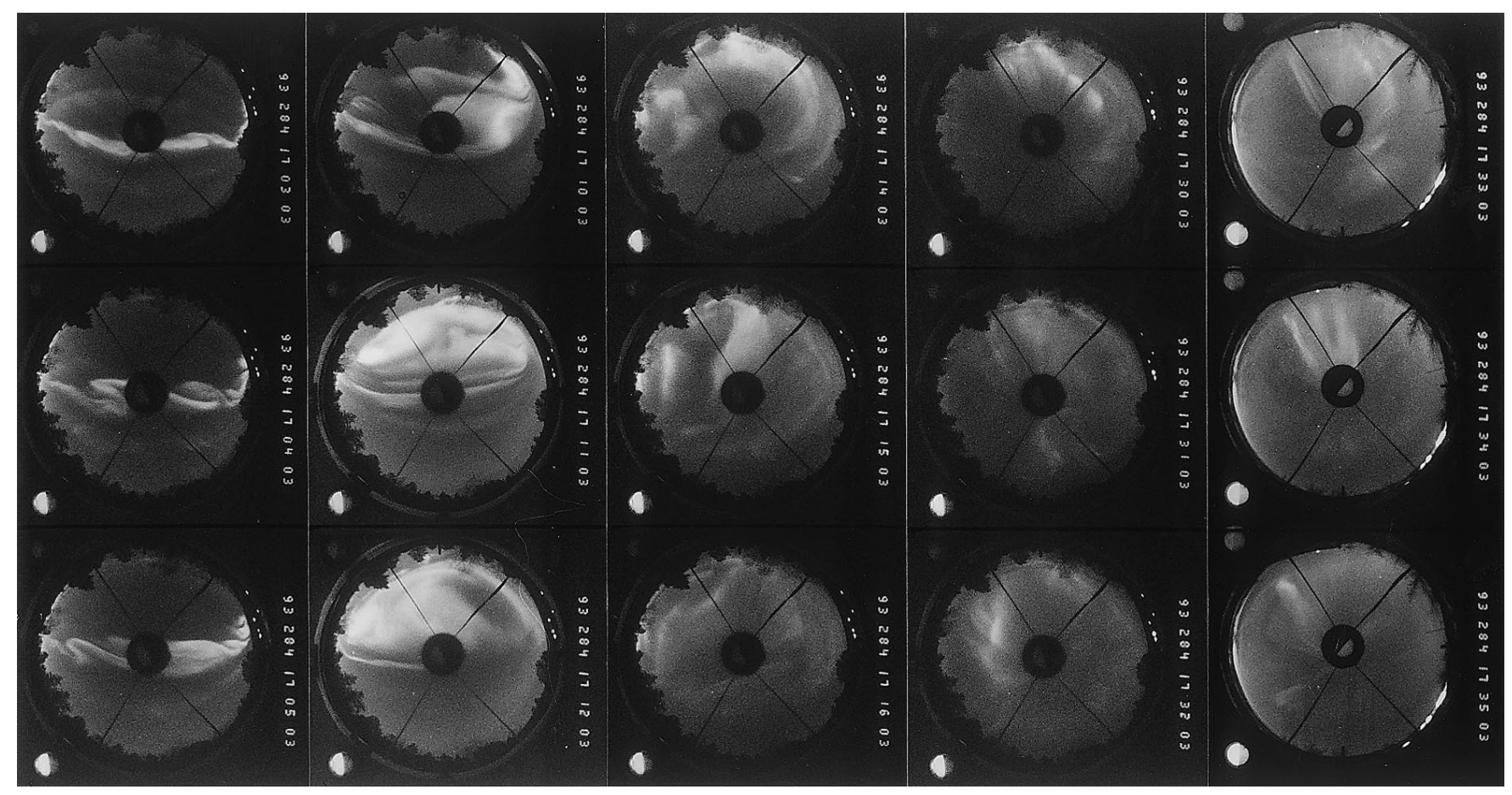

Fig. 7. Series of all-sky photos showing the prominent auroral features studied. The light conditions at KIL allow for reproducible pictures only after 1730 UT 
Plasma velocities have been acquired at four positions northward of Tromsø. The ionospheric footprints of the common volumes ranged from overhead Tromsø to a location $3.5^{\circ}$ further north (see Fig. 1). Figure 8 shows the two, northward and eastward, components of the plasma velocity at the four beam positions. VP1 denotes the position furthest north and VP4 the one just north of Tromsø.

At the beginning, just after 1500 UT, we had extremely high westward flows reaching almost $3 \mathrm{~km} / \mathrm{s}$ in the south. Later on they were lower but still westward in general. Only during 1700 to 1800 UT, the hour of interest, were the flow directions predominantly eastward. This is consistent with the first appearance of a westward electrojet over Scandinavia. Later on westward flows again dominated. The northward component of the flow varied about zero. During the hour under study it showed, however, a persistent southward component.

The other parameters obtained by EISCAT are the height integrated Hall and Pedersen conductivities, hereafter termed conductances. Raw densities integrated along the Tromsø beam have been used for their calculation, since the pulse code used was not well suited to determine the E-region electron temperature. Figure 9 shows the Hall conductances obtained at the four beam positions. The latitude difference between position P4, vertically above Tromsø, and position P1, furthest north, amounts to a little more than $1^{\circ}$. It has to be kept in mind that conductances were not sampled continuously. Due to beam swinging only an average, over about a minute, was taken at each position during the 5 min cycle period.

The conductances in the four panels of Fig. 9 reflect quite nicely all the different events which have been identified in the other data sets. Before the WTS the conductances are rather low except for the position P3. This is also the latitude where the largest conductances during the passage of the WTS $\left(\Sigma_{H}=50 \mathrm{~S}\right)$ were observed. Toward the north the WTS associated amplitudes became smaller and in the south (P4) there was no response at all.

The next prominent feature appeared around 1735 UT. Enhanced conductances coincided with the time when the second auroral feature passed the longitude of Tromsø. Largest amplitude are found here at highest latitudes. The conductance gradually levelled off within the next $10 \mathrm{~min}$. A correlation with the first auroral feature which would be expected at 1719 UT is not so obvious.

The $\Sigma_{H} / \Sigma_{P}$ ratio also shown in Fig. 9 can be considered as a measure for the mean energy of the precipitating electrons (Robinson et al., 1987). The ratio tends to approach 1 during periods of low conductances
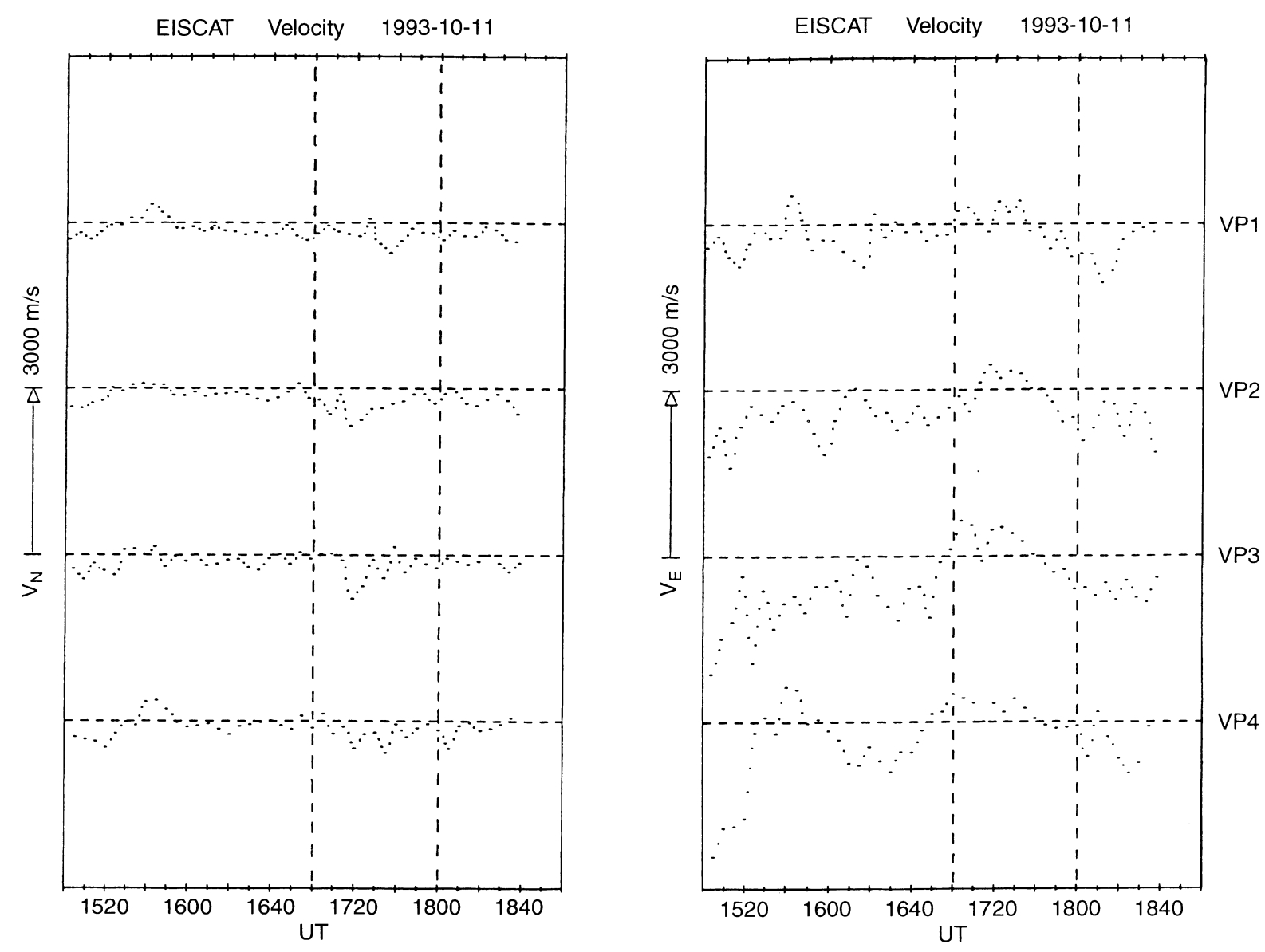

Fig. 8. Flow velocities obtained by EISCAT at four positions. The period of interest is marked by vertical lines 


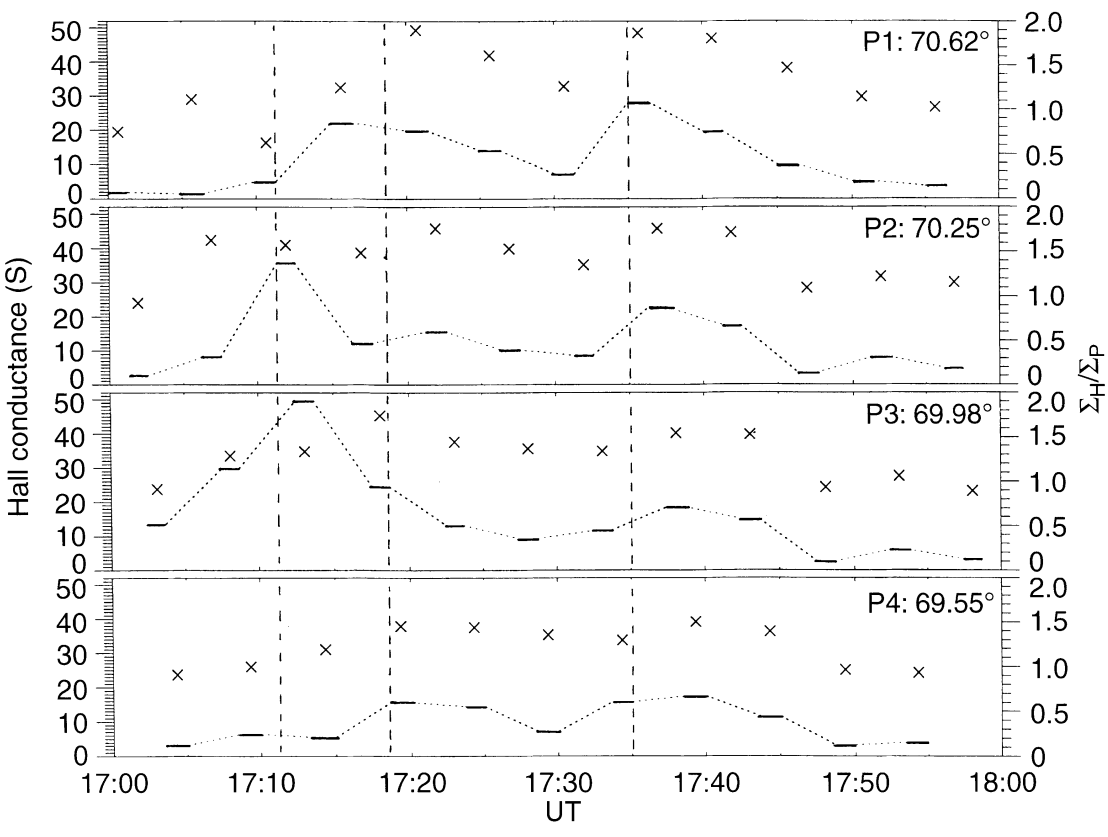

Fig. 9. Ionospheric conductivities obtained by EISCAT at four positions. The short vertical bars connected by dotted lines give the Hall conductance. Crosses mark the obtained Hall/ Pedersen conductance ratio. Passage of the auroral forms is marked by vertical lines and 2 for more active periods. The fairly low elevation beams (positions $\mathrm{P} 1: 43.6^{\circ}, \mathrm{P} 2: 55^{\circ}$ ) were gathered over a range of latitudes thus $\Sigma_{H}$ and $\Sigma_{P}$ are no longer collocated. In the case of P1 they are separated by about $20 \mathrm{~km}$. In particular, at the time of the WTS, when there are large conductivity gradients, the ratio shows quite a scatter (Fig. 9).

For a more direct comparison between magnetic field and EISCAT measurements Fig. 10 shows the horizontal component of the plasma velocity in a latitude versus time frame at the same scale as Figs. 5 and 6. During the hour following 17 UT we had a dominant southwesterly flow. Very clearly marked in the flow data is the WTS. Here the velocities at all positions approach zero. Also during the passage of the second auroral feature velocities become very small. Enhanced conductances seem to correlate with low velocities and vice versa. It has to be kept in mind, however, that the four conductivity measurements cover only the latitude band between the two southern velocity positions.

In the case of a homogeneous conductivity distribution in the ionosphere the plasma should flow in the opposite direction to the Hall current. Under the same conditions our equivalent currents, deduced from magnetic field deflections would represent the Hall current pattern. Hence, in that case, plasma flow and current vectors should point in opposite directions. A comparison between Figs. 5 and 10 clearly reveals that this condition is not fulfilled for most of the time. This situation is particularly obvious around the time of the second auroral feature (1735 UT). Before the event, both flows and currents have strong southward components and afterward the flows are small or weakly southward while there are strong northbound currents. All that suggests that there are steep conductivity gradients present prohibiting a simple interpretation of the equivalent currents.

\section{Interpretation}

In the previous section we presented the observations instrument by instrument. Now we will look at the data in a more event-orientated way. By combining the measurements from all instruments we hope to produce a picture that is as comprehensive as possible for different phenomena.

\subsection{Harang discontinuity}

Auroral images taken at KEV during the early minutes after 17 UT show a rather narrow luminous band running from east to west across the sky (see Fig. 7). Such auroral features appearing in the late evening

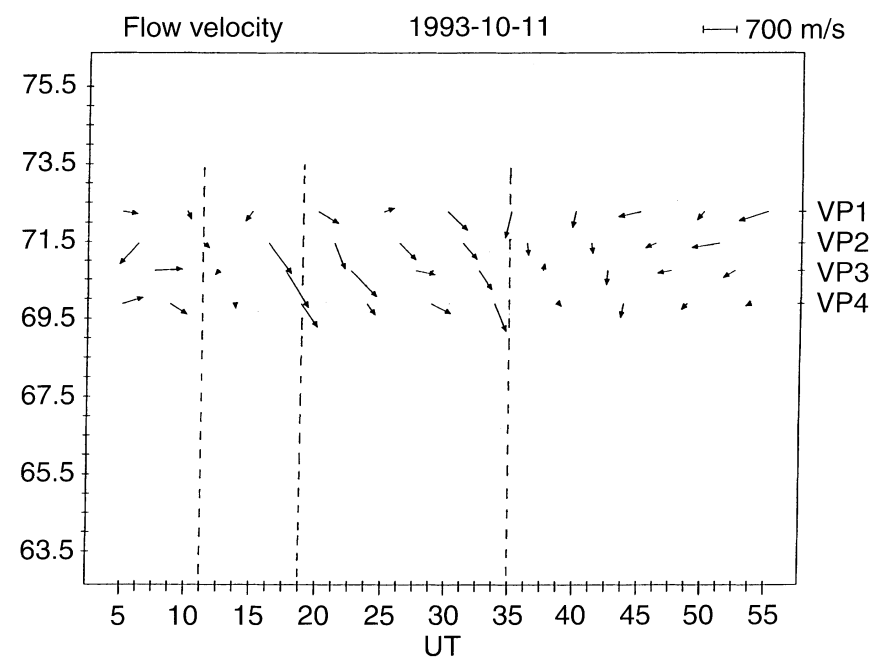

Fig. 10. Map of flow velocities obtained by EISCAT. Same format as Fig. 5, but no average flows subtracted 
hours have often been associated with the Harang discontinuity (HD) (Koskinen and Pulkkinen, 1995) which is the boundary between poleward and equatorward electric fields. The term Harang discontinuity has recently been controversially discussed concerning its definition. In spite of this debate we would like to use this term in its traditional sense, keeping in mind that it does not describe a plasma discontinuity but just the night-side flow reversal. In the magnetic field recordings the HD manifests itself as the zero crossing of the $\mathrm{X}$ component. In Fig. 3 we see that there is a zero crossing of $\mathrm{X}$ at SOR around $1704 \mathrm{UT}$ and at KEV the $\mathrm{X}$ component varies around zero for several minutes. The same is true for TRO (not shown here). All this is consistent with associating the auroral band with the HD.

The conductance measurements obtained by EISCAT show elevated values up to $\Sigma_{H}=30 \mathrm{~S}$ only at the P3 position, which is about $35 \mathrm{~km}$ north of the station TRO. Conductance values of this order have earlier been reported for the HD by Inhester et al. (1992) and Amm (1995). The fact that the conductivity is only enhanced in one of the beam positions which are separated by $40 \mathrm{~km}$, places narrow bounds on the width of the conductive strip. The north/south extent of the auroral band, estimated from Fig. 7 amounts to about $50 \mathrm{~km}$. For comparison, the diameter of the black circle in the centre of the all-sky pictures $\left(30^{\circ}\right)$ corresponds to $55 \mathrm{~km}$ at an altitude of $110 \mathrm{~km}$. This is another piece of evidence for the close relationship between luminosity and conductivity in the HD.

Well-developed HDs occur generally during the growth phase of a substorm. The subsequent expansion phase will be discussed in the next section.

\subsection{Westward travelling surge}

Westward travelling surges (WTS) have been studied for many decades. The reason why we include them here is that there are only a few examples of EISCAT measurements of a WTS in the literature.

The most convincing way to identify a WTS are auroral images. In Fig. 7 we see the rapid passage of an auroral bulge over KEV between 1710 and 1712 UT forming poleward of the pre-existing stable arc which we associated with the Harang discontinuity.

In the magnetic recordings WTSs exhibit positive deflections at all latitudes in the Y component whereas $\mathrm{X}$ shows negative deflections in the north and positive south of the surge head (see Fig. 3). A fast phase propagation particularly evident in the $\mathrm{Y}$ component implies a westward travel speed of the order of $10 \mathrm{~km} / \mathrm{s}$ for this event. The equivalent currents in the surge head are predominantly southward-oriented with eastward components in the south and westward in the north (see Fig. 5). This signature is very much the same as that reported by Opgenoorth et al. (1983).

Of particular interest for the study of this feature are the EISCAT measurements. Figure 9 shows a dramatic increase of the Hall conductance in the beam positions
$\mathrm{P} 2$ and $\mathrm{P} 3$ after the passage of the WTS. The peak value $\Sigma_{H}=50 \mathrm{~S}$ is observed at P3, the latitude of the preexisting Harang discontinuity. Only one beam position south of the maximum $(\sim 40 \mathrm{~km})$, at $\mathrm{P} 4$, there is no sign of any conductivity enhancement. These observations are fully compatible with EISCAT measurements of Kirkwood et al. (1988) who found the maximum of the Hall conductance (up to $75 \mathrm{~S}$ ) close to the southern edge of the surge. Conductivity gradients are very steep at the southern edge. Towards the north the conductivity slopes off more gradually (see Fig. 9). It should be stressed here that the WTS expended only poleward of the HD.

The plasma velocity is very low in the vicinity of the WTS (Fig. 10). At the latitude of the conductivity maximum we find velocities of only $80 \mathrm{~m} / \mathrm{s}$ corresponding to electric fields of $E=4 \mathrm{mV} / \mathrm{m}$. This again fits the value of $\mathrm{E}=5 \mathrm{mV} / \mathrm{m}$ reported by Kirkwood et al. (1988).

In an analytical model Amm (1955) combined all the observations of Kirkwood et al. (1988) and found a good agreement with their conclusions. One aspect of the Amm model, that we cannot confirm, is the conductivity ratio $\Sigma_{H} / \Sigma_{P}$ which he varied from 3.5 at the conductance peak to 1 in the unperturbed background. Our observations reveal ratios around 1.5 at all beam positions. A conductivity ratio of 3.5 would require an extremely high energy for the precipitating electrons which is not in accordance with reported observations. In all other points our measurements are in good agreement with the Amm (1995) model.

\subsection{Auroral streamers}

The auroral forms elongated in north-south direction, showing up overhead Kevo at 1715 and 1731 UT (see Fig. 7) are of special interest for this study. Both the auroral images and the magnetic recordings confirm that the features moved westward at a speed of $1.5 \mathrm{~km} / \mathrm{s}$. Similar features, also following a WTS, have earlier been observed by Oguti (1981) and Nakamura et al. (1993). These authors also report a westward motion but do not give the speed values Elphinstone et al. (1996) termed these westward propagating north-south aligned forms occurring in association with a double-oval configuration 'auroral streamers'.

Important observations for the interpretations of the auroral forms are provided by the EISCAT measurements. From the magnetic field data it was already suggested that the auroral patches were associated with upward FAC filaments. This suggestion could be confirmed by EISCAT conductance estimates. During both auroral events the $\Sigma_{H} / \Sigma_{P}$ ratio increased, implying that the spectrum of precipitating electrons became harder (Robinson et al., 1987) which is in favour with the formation of auroras. The stronger second event (1730 UT) was also associated with a significant increase in conductance (see Fig. 9).

We noted earlier the discrepancy between the time of passage of the upward FAC as determined from the 
magnetic field data and from the auroral images. Looking at the EISCAT measurements, we find that the signatures in the conductances coincide with the auroral observation, if propagation delays from KEV/ KIL to the EISCAT site are taken into account. All this provides further evidence that the equivalent currents cannot simply be interpreted as Hall currents in this kind of phenomena. Rather than using Eq. (3) a more rigorous treatment of the ionospheric electrodynamics is required to describe the relations of the various plasma parameters. According to Fukushima's (1976) theorem only divergence-free ionospheric currents contribute in an area of vertically incident field-aligned currents to magnetic field variations on the ground. At the auroral latitudes with inclinations around $80^{\circ}$ this condition is sufficiently well fulfilled. The source-free part of the ionospheric current which is reflected by the equivalent currents can be expressed as (e.g. Glaßmeier, 1987)

$(\operatorname{curl} \mathbf{J})_{z}=\Sigma_{H} \operatorname{div} \mathbf{E}-\left(\mathbf{E} \times \operatorname{grad} \Sigma_{P}\right)_{z}+\mathbf{E} \cdot \operatorname{grad} \Sigma_{H}$

here the subscript $z$ denotes the vertical component of the vector operator. All relevant quantities in Eq. (4) have been measured or can be derived. A full solution of this differential equation will be the subject of a later paper.

We have obtained measurements from magnetometers, all-sky cameras, and radars. Combining all these observations we are going to produce a picture of the auroral streamers that is as detailed as possible. In cases of moving structures, propagation delays have to be considered, if measurements from different sites are compared. The structure of the current features emerging from all our measurements is sketched in Fig. 11. All the observations have been related to a time that is valid along a meridian through the station KIL.

Basic elements of our interpretation are two pairs of anti-parallel FAC filaments. The centres of the upward directed FACs have liberally been collocated with the auroral streamers forms. These auroras appear at the westward (leading) edge of the regions of enhanced conductivity. The conductive patches are significantly larger than the auroral forms. The cause of this could be a time-of-light effect of the precipitating particles. Since the source region is moving, the fastest (highest energy) electrons will reach the ionosphere first and generate auroras at the leading edge. The low energetic tail arriving later and forming the trailing part is probably not energetic enough to excite auroras, but still enhances conductivity.

The equivalent current vortices do not surround the FAC filaments concentrically. Peak current densities are found to be rather well collocated with the boundary between high and low conductivity regions. In Fig. 11 the time scale has been converted into a spatial scale taking into account the propagation velocity. Comparing the dimensions in azimuthal and latitudinal directions reveals that the current vortices have a fairly circular shape.

Rather peculiar results emerge from the plasma flow measurements. As can be deduced from Fig. 10, the

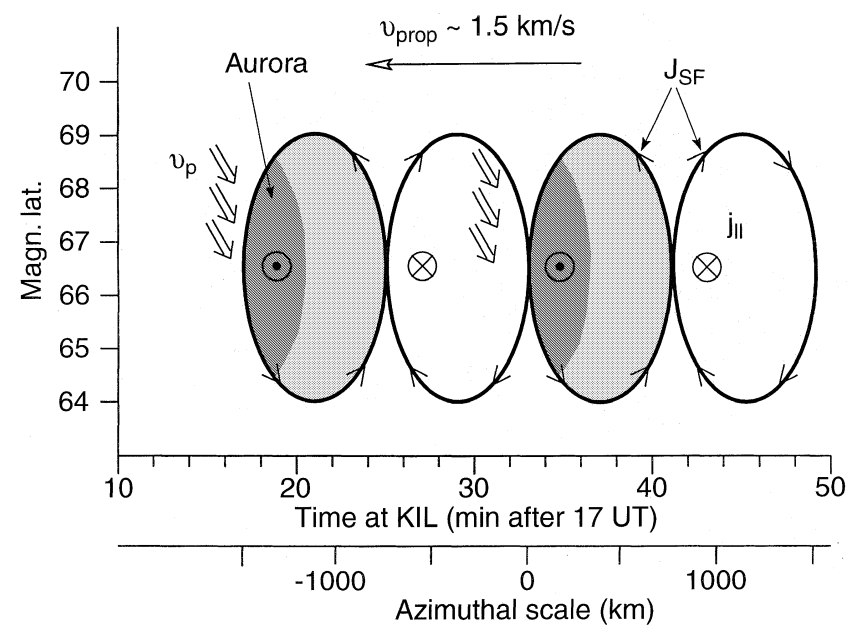

Fig. 11. Synoptic sketch of the electrodynamics associated with the westward moving auroral streamers. The azimuthal scale has been derived from the propagation speed of the auroral forms. For more details see Sect. 4.3

flows are generally south-eastward which is consistent with a position on the night-side of the dawn convection cell. The influence of the auroral patches on the ionospheric plasma flow is mainly a reduction of the velocity in high conductivity regions but only little change in direction is observed. High flow velocities $(\sim 700 \mathrm{~m} / \mathrm{s})$ were measured just in front of the steep conductivity gradients at the leading edges of the patches. It was expected, at least in the first case that equivalent currents and flow velocities point in opposite directions. What we find, in particular in regions where the flow speed peaks, is an almost parallel orientation, even if we take the mentioned uncertainty of some $30 \%$ in the east/west component of the flow velocities from the northernmost position VP1 into account.

An explanation for this apparent conflict could be that the background flows are so large compared to those associated with the vortices that the former are only insignificantly modified by the latter. An order-ofmagnitude estimate reveals for the expected changes in flow velocity

$v=\mathrm{J} /(\Sigma B)=400 \mathrm{~m} / \mathrm{s}$

if we insert such typical values, as $\mathbf{J}=0.2 \mathrm{~A} / \mathrm{m}$, $\Sigma=10 \mathrm{~S}$ and $\mathrm{B}=50000 \mathrm{nT}$, the resulting velocity cannot be regarded as small compared to the observed velocities. Other explanations, thus, have to be found.

The question arises: are our auroral streamers counterparts of $\Omega$-bands? The former appear to the west of the substorm current wedge and propagate westward while the latter form to the east and travel eastward. Both these auroral features have some characteristics in common. They form and move along the central latitude of a pre-existing electrojet. The scale size of both phenomena is of the order of $500 \mathrm{~km}$ and their velocity ranges around $1 \mathrm{~km} / \mathrm{s}$. There are also significant differences. While $\Omega$-bands are associated with flux tubes which are anchored in the ionosphere and move with the background plasma (Lühr and Schlegel, 1994), the 
features studied here show motions clearly different from the ionospheric plasma flow. Also the ionospheric plasma dynamics accompanying the two phenomena is quite different (Buchert et al., 1990). We tend to believe that the westward moving auroral streamers and the $\Omega$ bands are caused by quite different processes in the magnetosphere.

\section{Discussion}

In this section we discuss our observations in the larger context of magnetospheric processes. Westward moving transient features, besides WTS, can be observed rather frequently in association with pre-midnight substorms. For this reason we first present the characteristic of the substorm studied here.

\subsection{Substorm features}

The substorm commencing at 1710 UT ( 20 MLT) exhibits a number of features typical of evening-side substorms. The onset occurred at a fairly low latitude ( $\sim 66^{\circ}$ magnetic latitude). The associated westward electrojet moved poleward at an average speed of $1.2 \mathrm{~km} / \mathrm{s}$ (see Fig. 4). The poleward propagation seems to go in bursts rather than be continuous. After about $12 \mathrm{~min}$ the electrojet had reached its northernmost position at $75^{\circ}$ magnetic latitude and decayed thereafter rather rapidly.

By the time the initial jet had reached its northernmost position a new westward electrojet formed at lower latitudes $\left(\sim 67^{\circ}\right.$ magnetic latitude). This later jet did not move much but persisted for some $30 \mathrm{~min}$. It is with this jet that the westward moving auroral features were associated.

This kind of electrojet splitting can be observed quite frequently during evening-side substorms, and we may speculate that these two jets, going through rather different developments, are driven by two different processes in the magnetospheric tail. Several recent studies have been related to this phenomenon (e.g. Kotikov et al., 1995; Elphinstone et al., 1996).

The second electrojet starting some 10 min later may be driven by Earthward directed bursty bulge flows. Shiokawa et al. (1997b) have outlined the scenario for such a generation process which could also account for vortical flow patterns that might be responsible for the drifting auroral features.

\subsection{Transient features}

According to our data of the 11 October 1933 event, a WTS developed moving at about $10 \mathrm{~km} / \mathrm{s}$. Behind the surge in the "wake" large-scale FAC filaments are seen. In front of the surge there is a relatively narrow band of enhanced conductivity. The width is about $40 \mathrm{~km}$. Inside the band $\Sigma_{H}$ and $\Sigma_{P}$ reach about $15 \mathrm{~S}$, outside of the band their values are below $4 \mathrm{~S}$. The band is probably the westward continuation of the stable arc seen in the all-sky camera records.

In the head of the surge the conductivities rise to about 50 and $36 \mathrm{~S}$ for Hall and Pedersen, respectively. In the wake Pedersen conductivities vary between 7 and $15 \mathrm{~S}$, Hall between 8 and $28 \mathrm{~S}$, their maxima are around the centres of the upward currents. Relatively high conductivities are observed even at the most northern EISCAT antenna positions but not south of the head.

The electric field is strongest behind the surge head. It increases from a value below $5 \mathrm{mV} / \mathrm{m}$ inside to about $50 \mathrm{mV} / \mathrm{m}$ pointing towards south-west. Then both the east-west and the north-south components seem to be modulated by the sequence of up and downward FAC filaments. In front of the surge most flow vectors are eastward. Both the surge and the slower FAC filaments move against the average plasma flow in the current wedge.

Our clear observation of a southwestward electric field behind the surge stands out somewhat when compared with other experimental works. Horwitz et al. (1978) derived a north-westward electric field from measurements with a monostatic incoherent scatter radar in a comparable situation. Coherent radars did not return echoes within an elongated area behind surges (Inhester et al., 1981; Opgenoorth et al., 1983). The authors concluded that the field strength was below a threshold of $15 \mathrm{mV} / \mathrm{m}$. The field seen in this event is above such a threshold. The radars did indicate a southward field beyond the poleward edge of the surge wake.

Some phenomenological models, for example Boström's (1964) type I, postulate a mainly westward field behind the head of the current wedge as part of the magnetosphere-ionosphere current circuit, while in his type II current system it is southward. In a model for substorms by Haerendel (1992) the energy which is transported by the current systems into the ionosphere and atmosphere comes from the braking of Earthward flowing plasma in the plasma sheet. In a recent study Shiokawa et al. (1997a) have provided experimental evidence for this concept by examining AMPTE/IRM data. Using our measured value of the Pedersen conductance and electric field, the height-integrated current behind the surge is estimated to about $0.4 \mathrm{~A} / \mathrm{m}$. Most of this current seems to continue as upward FAC above the surge head. It flows over about 2 degrees in latitude. Then the total current amounts to roughly $80 \mathrm{kA}$, quite in accordance with Haerendel's (1992) estimate from plasma sheet parameters. Due to partial current closure in the acceleration region, to be discussed in the next paragraph the generator is probably stronger than inferred from the ground-based observations.

Our relatively complete ground-based data set gives a rather comprehensive picture of the event at the ionospheric level. However, a mapping of these observations to the magnetosphere, even qualitatively, is certainly of limited accuracy. The high conductivities are caused by ionisation through accelerated electrons with energies of several keV. A simple semi-empirical formula 
by Robinson et al. (1987) gives, for the observed highest ratio $\Sigma_{H} / \Sigma_{P} \sim 2$, an energy of about $5 \mathrm{keV}$. Most of the proposed acceleration mechanisms involve the maintenance of parallel electric fields accompanied by dissipation at an altitude of roughly 1 Re concentrated in the areas of upward FAC. Such processes would considerably reduce the convergent perpendicular electric field below the acceleration region compared to the one above it, in other words, the magnetospheric flow becomes partially decoupled from the ionospheric one.

Mapping along dipolar field lines, Nakamura et al. (1993) derived qualitatively the flow in the equatorial plane for another event which was quiet similar to the one presented here (their Fig. 11d). The FAC structures in the wake of our surge on 11 October 1993 are more circular in shape than the north-south aligned aurora seen by Nakamura et al. (1993), but nevertheless might be the same type of phenomenon. In the presence of field-aligned potentials which are implied by our conductivity measurements such a derived flow pattern would need to be considerably modified. It is beyond the scope of this study to speculate in what way.

Adding another complication to ionosphere-magnetosphere coupling, we point out that self-induction of ionospheric current vortices becomes significant at the spatial scales and temporal rates resolved by our data. Currents closing within the ionosphere, i.e. current vortices, which are to a first approximation Hall currents, have a corresponding magnetic field perturbation in the $z$ direction. Changes of $B_{z}$ in time imply, by Faraday's law, a rotational electric field. Such a field would be observed by ground-based radars. However, having only the single point measurement of EISCAT, a distinction between rotational and convergent/divergent components of the field is not possible for this event. Figure 12 depicts schematically a simple scenario of such a self-induction. An increasing, purely westward, magnetospheric field would drive a growing northward Hall current. Using Lenz's law, the induction field is then southward, the total electric field rotated counterclockwise when viewed from above. The most rapid increase of the electric field is, as already mentioned, observed directly after the passage of the surge. With the preceding arguments part of the measured field might

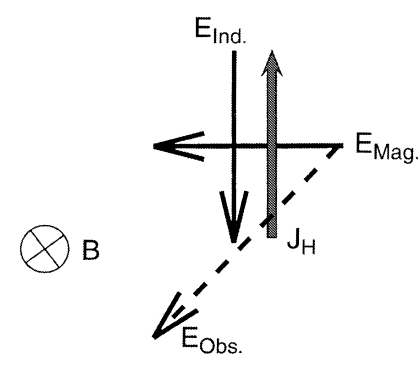

Fig. 12. Schematic explanation of self-induction in the ionosphere behind the surge. When the westward convection field, $E_{M a g}$ increases in time, it drives a Hall current $j_{H}$ which also increases in time. The induced field $E_{\text {Ind }}$ opposes this change, according to Lenz's law, and is southward. Then the total, observed electric field, $E_{O b s}$, is rotated towards south and larger than the original field $E_{M a g}$ then be due to the induction effect and the magnetospheric electric field more westward than southward. An order of magnitude estimate is obtained using

$E_{\text {ind }} \sim \mu_{0} L^{2} / T \sigma_{H} E_{m}=\mu_{0} v L \sigma_{H} E_{m}$

where $L$ and $T$ are typical length and time scales of the variations of the magnetospheric field $E_{m}$. Inserting $v=12 \mathrm{~km} / \mathrm{s}$ for the travel speed of the surge, $L=200$ $\mathrm{km}$, and $\sigma_{H}=5 \cdot 10^{-4} \mathrm{~S} / \mathrm{m}$, an electric field $E_{\text {ind }} \sim 1.5 E_{m}$ is obtained. Note, the self-induced field at the $\mathrm{E}$ region is of the same order as the convection field. This rotational field decreases exponentially with distance from the ionosphere with a scale $L$, since it continues in the magnetosphere as a fast mode which is evanescent (Hughes, 1983). The field vector measurements were made at a height about $170 \mathrm{~km}$, above the maximum of the Hall conductivity. This is within a typical horizontal scale size, and therefore the observed field probably still has a considerable rotational component. This component also drives a divergent Hall current which must close transiently in the magnetosphere. The effects of $\partial B / \partial t \neq 0$ are discussed in more detail by Buchert and Budnik (1997).

In summary, we have presented the observation of a westward travelling surge followed by large-scale FAC filaments with a very complete set of ground-based instruments. Tentatively, the FAC filaments, although more circular in shape, are associated with the northsouth aurora observed by Nakamura et al. (1993) in another event, and we propose that they are a usual phenomenon behind surges. In this event, there is clear evidence of a strong electric field after the passage of the surge still in the region of relatively high conductivities. Such a field is postulated by models for magnetosphere/ ionosphere current systems in substorms. The increase of the conductivities and of the ratio of Hall to Pedersen conductivities suggest the presence of parallel electric fields in particular above the surge, but also above the FAC filaments. We point out that although the existence of such field-aligned potential drops has been suggested since decades and is more or less confirmed by in-situ measurements, models and theory provide still relatively little guidance for the mapping of our ionospheric measurements into the magnetosphere. Finally we mention that at the observed dynamic scales the effects of self-induction in time-varying ionospheric currents become significant and need to be studied in more detail.

Acknowledgements. The IMAGE magnetometer network is a cooperative effort of nine institutions from six European countries. We are very much obliged to the many people who make the IMAGE project a success by their continuous support: A. Viljanen (PI), L. Häkkinen, H. Nevanlinna and R. Pellinen (Finnish Meteorological Institute), J. Kultima and P. Vilkki (Sodankylä Geophysical Observatory), T.L. Hansen (University of Tromsø), A. Grafe and H.J. Linthe (GeoForschungsZentrum Potsdam), S.-E. Hjelt (University of Oulu), W. Glegolski and J. Reda (Polish Academy of Sciences) and K.-H. Glaßmeier and C. Willecke (Technical University of Braunschweig). The EISCAT Scientific Association is supported by the Max-Planck-Gesellschaft (Germany), Centre National de la Recherche Scientifique (France), Science and Engineering Research Council (UK), Norges Al- 
menvitenskapelige Forskningsrad (Norway), Naturvetenskapliga Forskingsradet (Sweden), and the Suomen Akatemia (Finland).

Topical Editor D. Alcaydé thanks C. Senior and another referee for their help in evaluating this paper.

\section{References}

Akasofu, S.-I., D. S. Kimball, and C.-I. Meng, The dynamics of the aurora, 2. Westward traveling surges, J. Atmos. Terr. Phys., 27, 173-187, 1965.

Amm, O., Direct determination of local Hall conductance distribution from two-dimensional electric and magnetic field data: application of the method using models of typical ionospheric electrodynamic situations, J. Geophys. Res., 100, 21473-21488, 1995.

Baker, K. B., and S. Wing, A new magnetic coordinate system for conjugate studies at high latitudes, J. Geophys. Res., 94, 91399143, 1989.

Birkeland, K., The Norwegian Aurora-Polaris expedition 1902 1903, Christiana 1, 1908.

Boström, R., A model of the auroral electrojets, J. Geophys. Res., 69, 4983-4999, 1964

Buchert, S. C, and F. Budnik, Field-aligned current distributions generated by a divergent Hall current, Geophys. Res. Lett., 24, 297-300, 1997.

Buchert, S., G. Haerendel, and W. Baumjohann, A model for the electric fields and currents during a strong Ps6 pulsation event, J. Geophys. Res., 95, 3733-3743, 1990.

Chapman, S., The electric current-system of magnetic storms, Terr. Magn. Atmos. Electr., 40, 349-370, 1935.

Elphinstone, R. D., J. S. Murphree, and L. L. Cogger, What is a global auroral substorm?, Rev. Geophys., 34, 169-232, 1996.

Friis-Christensen, E., M. A. McHenry, C. R. Clauer, and S. Vennerstrøm, Ionospheric travelling convection vortices observed near the polar cleft: a triggered response to sudden changes in the solar wind, Geophys. Res. Lett., 15, 253-256, 1988.

Fukushima, N., Ground magnetic effect of field-aligned currents connected with ionospheric currents, Rep. UT-GRL-76-01, University of Tokyo, Tokyo, 1976.

Glaßmeier, K.-H., Ground-based observations of field-aligned currents in the auroral zone: methods and results, Ann. Geophysical, 5, 115-125, 1987.

Glaßmeier, K.-H., M. Hönisch, and J. Untiedt, Ground-based and satellite observations of traveling magnetospheric convection twin-vortices, J. Geophys. Res., 94, 2520-2528, 1989.

Haerendel, G., Disruption, ballooning or auroral avalanche-on the cause of substorms, in Substorms 1, pp 417-420, ESA SP-335, 1992.

Horwitz, J. L., J. R. Doupnik, and P. M. Banks, Chatanika radar observations of the latitudinal distributions of auroral zone electric fields, conductivities, and currents, J. Geophys. Res., 83, 1463-1481, 1978

Hughes, W. J., Hydromagnetic waves in the magnetosphere, in Solar-Terrestrial Physics, Eds. R. L. Carovillano and J. M. Forbes, pp. 453-477, Reidel, 1983.
Inhester, B., W. Baumjohann, R. A. Greenwald, and E. Nielsen, Joint two-dimensional observations of ground magnetic and ionospheric electric fields associated with auroral zone currents, 3. Auroral zone currents during the passage of a westward traveling surge, J. Geophys., 49, 155-162, 1981.

Inhester, B., J. Untiedt, M. Segatz, and M. Kürschner, Direct determination of the local ionospheric Hall conductance distribution from two-dimensional electric and magnetic field data, J. Geophys. Res., 97, 4073-4083, 1992.

Kirkwood, S., H. J. Opgenoorth, and J. S. Murphree, Ionospheric conductivities, electric fields and currents associated with auroral substorms measured by the EISCAT radar, Plant. Space. Sci., 36, 1359-1380, 1988.

Koskinen, H. E. J., and T. I. Pulkkinen, Midnight velocity shear zone and the concept of Harang discontinuity, J. Geophys. Res., 100, 9539-9547, 1995.

Kotikov, A. L., E. M. Shishkina, O. A. Troshichev, and T.I. Sergienko, Double structure of ionospheric conductivity in the midnight auroral oval during a substorm, J. Atmos. Terr. Phys., 57, 177-186, 1995.

Lühr, H., The IMAGE magnetometer network, in STEP International, 4, USSCO, Oct., 1994.

Lühr, H., and K. Schlegel, Combined measurements of EISCAT and EISCAT magnetometer cross to study $\Omega$ bands, J. Geophys. Res., 99, 8951-8959, 1994.

Lühr, H., S. Thürey, and N. Klöcker, The EISCAT-Magnetometer Cross: operational aspects, first results, Geophys. Surv., 6, 305$315,1984$.

Nakamura, R., T. Oguti, T. Yamamoto, and S. Kokubun, Equatorward and poleward expansion of the aurora during auroral substorms, J. Geophys. Res., 98, 5743-5759, 1993.

Oguti, T., TV observations of auroral arcs, in Physics of Auroral Arc Formation, eds. S.-I. Akasofu and J. R. Kann, AGU Geophys. Mongr. 25, 31-41, Washington, 1981.

Opgenoorth, H. J., R. J. Pellinen, W. Baumjohann, E. Nielsen, G. Marklund, and L. Eliasson, Three-dimensional current flow and particle precipitation in a westward travelling surge (observed during the Barium-GEOS rocket experiment), J. Geophys. Res., 88, 3138-3152, 1983.

Robinson, R. M., R. R. Vondrak, K. Miller, T. Dabbs, and D. Hardy, On calculating ionospheric conductances from the flux and energy of precipitating electrons, J. Geophys. Res., 92, 2565-2569, 1987.

Shiokawa, K., W. Baumjohann, and G. Haerendel, Breaking of high-speed flows in the near-Earth tail, Geophys. Res. Lett., 24, 1179-1182, 1997a.

Shiokawa, K., W. Baumjohann, G. Haerendel, J. F. Fennell, E. FriisChristensen, H. Lühr, T. Nagai, G. Paschmann, G. D. Reeves, C. T. Russell, P. R. Sutcliffe and K. Takahashi, Relations of highspeed ion flow, substorm current wedge, and multiple Pi2 pulsations during a substorm on March 1, 1985, J. Geophys. Res., (accepted), 1997b.

Untiedt, J. and W. Baumjohann, Studies of polar current systems using the IMS Scandinavian magnetometer array, Space Sci. Rev., 63, 243-390, 1993. 